\title{
LOW CRYSTALLINITY NANOHYDROXYAPATITE PREPARED AT ROOM TEMPERATURE
}

\section{AURORA MOCANUa, REKA BALINT ${ }^{a}$, CORINA GARBO ${ }^{a}$, LUCIA TIMIS ${ }^{a}$, IOAN PETEAN ${ }^{a}$, OSSI HOROVITZa, MARIA TOMOAIA-COTISEL ${ }^{a *}$}

\begin{abstract}
In order to obtain a low crystalline nanohydrxyapatite (HAP), suitable for biomedical application, a new synthesis procedure was developed, based on the aqueous precipitation method, at room temperature, without any additives. Accordingly, lyophilized HAP powders, both calcined and non calcined, were prepared, and characterized by XRD, TEM and AFM imaging, FTIR spectroscopy, zeta potential and BET measurements. The results confirmed HAP as the only phase present. The high porosity of this nanomaterial is attained. The nanoparticle size and shape as well as the crystallinity degree of the obtained HAP samples were also determined.
\end{abstract}

Keywords: nanohydroxyapatite, chemical synthesis, XRD, TEM, AFM, FTIR, $B E T$

\section{INTRODUCTION}

Hydroxyapatite, $\mathrm{Ca}_{10}\left(\mathrm{PO}_{4}\right)_{6}(\mathrm{OH})_{2}$, (HAP) is a preferred material for hard tissue replacement, due primarily to its bioactivity and biocompatibility. Most physical and chemical properties of synthetic hydroxyapatite are largely influenced by the preparation conditions. Wet chemical methods are considered as most capable to achieve controlled shapes and sizes of HAP particles, by

\footnotetext{
a Babeş-Bolyai University, Faculty of Chemistry and Chemical Engineering, 11 Arany Janos str., RO-400028, Cluj-Napoca, Romania,

*Corresponding author: mcotisel@gmail.com
} 
the variation of synthesis parameters [1]. In the precipitation method, based on the reaction of calcium nitrate and diammonium hydrogen phosphate in aqueous solutions at basic $\mathrm{pH}$ (over 10), a rather long maturation stage is needed for their full conversion to the less soluble and thermodynamically most stable product, HAP, with a high crystallinity degree [2]. But here we are interested in a small size of nanoparticles and low crystallinity, which jointly with a high porosity of the material should assure a good biological activity, for potential biomedical use. Following our syntheses of different calcium phosphates, more or less substituted [3-5], we designed a preparation procedure for pure HAP, without the addition of other substances, at room temperature, and without maturation at higher temperatures.

\section{RESULTS AND DISCUSSION}

$X$-ray diffraction patterns were obtained for the noncalcined (sample A) and calcined (sample B) lyophilized HAP powders. In Figure 1 the spectra for sample A and sample B are compared with the PDF 74-0565 for stoichiometric hydroxyapatite. For both samples, hydroxyapatite is the only crystalline phase present. The calcination at $300^{\circ} \mathrm{C}$ could not bring about a conversion to $\beta$-tricalcium phosphate, which might be possible only at much higher temperatures. The highest peak occurs at a $2 \theta$ value about $32^{\circ}$, and corresponds to the (211) peak of HAP [6]. Rather broad peaks are observed in Fig. 1.

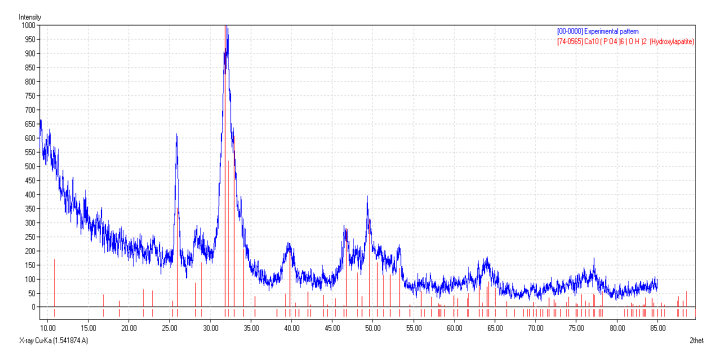

a

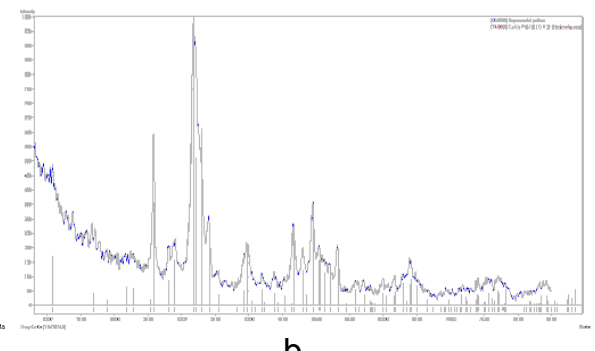

b

Figure 1. XRD patterns for sample $A(a)$ and sample $B(b)$, compared with PDF 74-0565 for stoichiometric hydroxyapatite

Such peaks can result from either a poor crystallinity or a very small crystal size [7], and for small crystallites it is difficult to discriminate between these two factors [8]. The crystallite domain is estimated as $13.8 \mathrm{~nm}$ (sample A), and $15.1 \mathrm{~nm}$ (after calcination, sample B), while the crystallinity degree is $21.3 \%$ 
(A), respectively $23.1 \%(B)$, so here both causes apply. For a fast mixing of reactants, as in our experiments, the decreased HAP crystallinity was also observed [9], as an outcome of the supersaturation and local inhomogeneity resulted from the rapid mixing of the phosphate and the calcium containing solutions. Calcination brings about a slight increase, both in crystallite size and crystallinity degree, as found also for related situations [10].

TEM images for the aqueous dispersion of sample A (an example in Fig. 2) show acicular (rod-like) formations, which at higher resolution prove to be filiform assemblies of small nanoparticles. Most of these needles have a length in the range of $50-70 \mathrm{~nm}$, while a few attain even over $100 \mathrm{~nm}$; their diameter is the diameter of a nanoparticle, namely about $10 \mathrm{~nm}$. These observations are similar to those found in the state of the art for related systems. Rod-shaped crystals with diameters $10-60 \mathrm{~nm}$ and lengths $200-500 \mathrm{~nm}$ were observed for HAP obtained at a temperature of $37^{\circ} \mathrm{C}$, aged overnight, and air dried [11]. Rods formed by smaller particles with sizes around $5 \mathrm{~nm}$ were also observed [7].

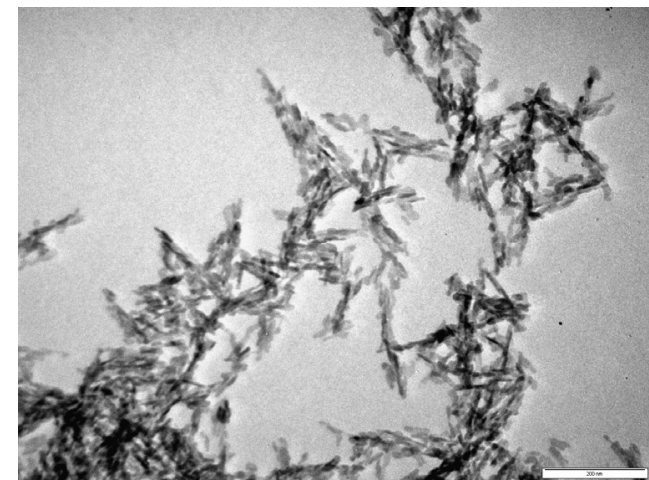

a

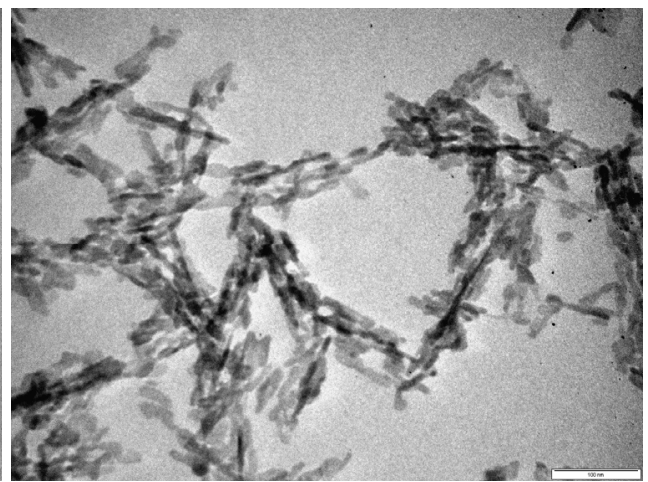

b

Figure 2. TEM images of sample A dispersed in water; the bars in the images are $200 \mathrm{~nm}$ (a), and $100 \mathrm{~nm}$ (b)

The FTIR spectra are compared in Figure 3 for lyophilized samples without calcination (A) and after calcination at $300^{\circ} \mathrm{C}$ for $1 \mathrm{~h}(\mathrm{~B})$. The spectra were normalized to 1 for the highest absorption peak and shifted along the $y$ axis for comparison. The characteristic absorption bands corresponding to the vibrations of the $\mathrm{PO}_{4}$ and $\mathrm{OH}$ groups of hydroxyapatite are present. 


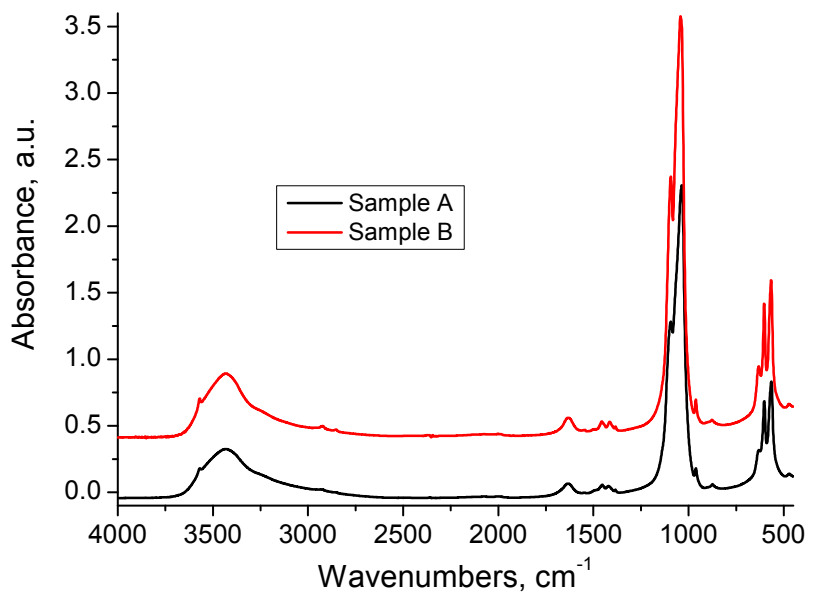

Figure 3. FTIR spectra of lyophilized samples without calcination (A) and after calcination (B); the spectra are normalized

The most intense band is that corresponding to the asymmetric $\mathrm{PO}_{4}$ stretching mode $\mathrm{v}_{3}$; it has two peaks: the highest at $1036(\mathrm{~A})$, and $1043 \mathrm{~cm}^{-1}(B)$, the lower at 1093-1094 $\mathrm{cm}^{-1}$. They are characteristic for stoichiometric HAP, but the presence of type $B$ carbonate substitution (wave number $1045 \mathrm{~cm}^{-1}$ ) could contribute to the shift of one of the main peak to higher wave numbers [12]. The symmetric $\mathrm{PO}_{4}$ stretching mode $\mathrm{v}_{1}$ is IR-inactive for the ideal tetrahedral symmetry $\left(T_{d}\right)$ of the group, but the deformation of the $\mathrm{PO}_{4}$ tetrahedron in the apatite lattice lowers its symmetry [13,14], so an absorption peak appears with low intensity at $962 \mathrm{~cm}^{-1}$. The bending modes of $\mathrm{PO}_{4}$ appear at lower wave numbers. The asymmetric bending $v_{4}$ (triply degenerate for $T_{d}$ symmetry) [15] generates a band with two peaks, at 565-567 and 603-604 $\mathrm{cm}^{-1}$. The symmetric bending mode $v_{2}$ gives only a low intensity maximum at $472-473 \mathrm{~cm}^{-1}$.

The characteristic $\mathrm{OH}$ peaks appear at $3569-3570$ and $632-633 \mathrm{~cm}^{-1}$ and are an indication for the appropriate stoichiometric ratios in the synthesis of HAP $[16,17]$. The first peak is due to a stretching $\mathrm{OH}$ vibration $[18,19]$ and is superposed on the broad band with maximum at $3431-3433 \mathrm{~cm}^{-1}$ due to $\mathrm{O}-\mathrm{H}$ stretching vibrations in absorbed water molecules [20] with hydrogen bonding $\mathrm{O}-\mathrm{H} . . . \mathrm{O}$ in the samples. The HAP OH band appears more distinct in the calcined sample (B), probably because of a partial loss of absorbed water by calcination, and a corresponding diminution of its broad absorption band. The peak at $632 \mathrm{~cm}^{-1}$ corresponds to the $\mathrm{OH}$ libration band. The band at $1633-1635 \mathrm{~cm}^{-1}$ originates from absorbed water. 
The bands at $1455-1457.1415-1421$ and $875-878 \mathrm{~cm}^{-1}$ are assigned to $\mathrm{CO}_{3}{ }^{2-}$ (asymmetric stretching $\mathrm{v}_{3}$ and out of plane bending $\mathrm{v}_{2}$ the last) [21], originated from the interactions of HAP with $\mathrm{CO}_{2}$ absorbed by the samples from the atmospheric air. In the samples calcined at $300^{\circ} \mathrm{C}$ these bands are attenuated.

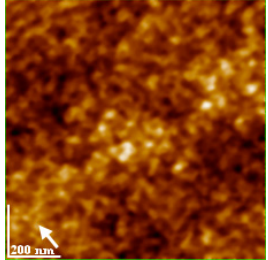

a

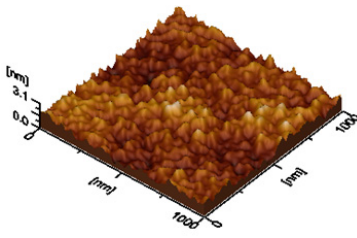

b

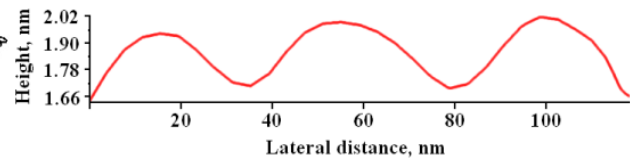

C

Figure 4. AFM images for sample B adsorbed on glass support for $10 \mathrm{~s}$ : 2D- topography (a), 3D-topography (b) and cross section profile (c) along the arrow in panel (a); scanned area of $1 \mu \mathrm{m} \times 1 \mu \mathrm{m}$.

Carbonated HAP can contain $\mathrm{CO}_{3}^{2-}$ ions substituting for $\mathrm{OH}^{-}$(type A) or for $\mathrm{PO}_{4}{ }^{3-}$ (type $\mathrm{B}$ ). While biological apatites are mostly type $\mathrm{B}$, synthetic HAPs are of mixed type (AB) [22]. The bands ca. 1415 and $1450 \mathrm{~cm}^{-1}$ are characteristic for type $\mathrm{B}$ or $\mathrm{AB}$ [23]. The presence of $\mathrm{CO}_{3}{ }^{2-}$ may improve the bioactivity of HAP rather than being a cause of concern [24].

In the spectra of our samples are missing the bands assigned to vibrations of non-apatitic $\mathrm{HPO}_{4}^{2-}$ ion, at $530-540 \mathrm{~cm}^{-1}[12,25]$ or 1125 and $1145 \mathrm{~cm}^{-1}$ [12], as well as maxima characteristic for non-stoichiometric apatites $\left(1018 \mathrm{~cm}^{-1}\right)$ [12]. This confirms the phase purity of the obtained HAP samples, as evident also from the XRD patterns.

Some typical AFM images are given in Figure 4 for the calcined HAP sample (B). They include 2D and 3D topographical images, and cross section profiles along selected directions in the $2 \mathrm{D}$ topography. The images are consistent with the results of TEM and XRD investigations regarding the shape and size of nanoparticles.

The samples presented low positive zeta potential values. For instance the lyophilized not calcined sample $A$ had $\zeta=6.71 \mathrm{mV}$. This positive potential could be a consequence of ionization (release of $\mathrm{OH}^{-}$ions in the solution).

The BET measurements revealed a rather high specific surface area: $144 \mathrm{~m}^{2} / \mathrm{g}$ for the not calcined sample. By calcination the specific surface area is diminished to $91 \mathrm{~m}^{2} / \mathrm{g}$, as an effect of nanoparticles sintering, while the pores specific volume is rather unchanged $\left(0.332\right.$, respectively, $\left.0.361 \mathrm{~cm}^{3} / \mathrm{g}\right)$. The values are comparable with reported data for related circumstances [26]; 
for instance "as precipitated" HAP made at room temperature was reported to possess a surface area of $90 \mathrm{~m}^{2} / \mathrm{g}$, after oven drying, and $113 \mathrm{~m}^{2} / \mathrm{g}$ after freeze-drying [27]. The adsorption-desorption isotherms are of type IV. The most probable pore radius was $7.7 \mathrm{~nm}$, so the samples can be classified as mesoporous materials, according to the IUPAC notation [28], with pore diameters between 2 and $50 \mathrm{~nm}$. Since the nanoparticles themselves (TEM images) are not porous, this porosity results mainly from the agglomerations of nanoparticles.

\section{CONCLUSIONS}

The proposed chemical preparation method, by precipitation in aqueous phase, without any organic and inorganic additives (surfactants, templates), at room temperature and without a long maturation stage resulted in a low crystallinity nanostructured hydroxyapatite. Together with its high porosity, these properties should assure a good biological activity, which recommend this material for biomedical applications, along with substituted hydroxyapatites, containing silicon [29], zinc [26], strontium [30], magnesium [5] or silver [31].

\section{EXPERIMENTAL SECTION}

Nanostructured hydroxyapatite was prepared by a simple method, starting with two solutions: (a) a $0.25 \mathrm{M}$ calcium nitrate solution, obtained from $\mathrm{Ca}\left(\mathrm{NO}_{3}\right)_{2} \cdot 4 \mathrm{H}_{2} \mathrm{O}$ (pure p.a., Merck) dissolved in ultrapure water, with $25 \%$ ammonia solution, in order to assure a $\mathrm{pH}$ value of 8.5 , and (b) a $0.15 \mathrm{M}$ diammonium hydrogen phosphate solution, prepared from $\left(\mathrm{NH}_{4}\right)_{2} \mathrm{HPO}_{4}$ (pure p.a., Sigma-Aldrich) dissolved in ultrapure water, with $25 \%$ ammonia solution added to assure a $\mathrm{pH}$ value of 11 . The two solutions, at room temperature $\left(22^{\circ} \mathrm{C}\right)$, were quickly mixed, using a peristaltic pump and an impact reactor type $Y$ for the two fluid streams, containing the reactants in stoichiometric ratio.

The obtained dispersion, without any subsequent treatment, in the presence of the mother liquor, was filtered (Filter Disks Munktell, grade: 382), and washed with ultrapure water (until no nitrate ions were detected). A wet precipitate (paste) was obtained. Sample A (lyophilized powder) was prepared by further processing of the precipitate: it was dried by lyophilization (freeze drying) at $-50^{\circ} \mathrm{C}$ at a pressure of $0.040 \mathrm{mbar}(0.03$ torr), and the obtained material was dispersed by grinding in an agate mortar. Sample $B$ (calcined lyophilized powder) was obtained by calcination of sample $\mathrm{A}$ at $300^{\circ} \mathrm{C}$ (for $1 \mathrm{~h}$ ). 
The samples were characterized by $X$-Ray Diffraction (XRD) investigations used a DRON-3 diffractometer, in Bragg-Brentano geometry, equipped with a X-ray tube with Co $\mathrm{K}_{\alpha}$ radiation (wavelength $1.79026 \AA$ ), $25 \mathrm{kV} / 20 \mathrm{~mA}$. Phases were identified by comparing the peak positions of the diffraction patterns with PDF files such as PDF 74-0566 for stoichiometrical HAP. The average crystallite size for these samples was evaluated by the Scherrer method, from the width of the most intense diffraction peaks, measured at half-maximum. The crystallinity degree of the samples was also estimated.

The samples were observed with a transmission electron microscope (TEM, JEOL - JEM 1010). The HAP aqueous dispersion of sample A (paste), needed for TEM imaging, was prepared by ultrasonification, using a high intensity ultrasonic processor Sonics Vibra-Cell, model VCX 750, for 5 minutes, at room temperature. From their aqueous dispersion, the particles were adsorbed on the specimen grids, while the excess solution was removed with filter paper and the samples were air dried. TEM images have been recorded with JEOL standard software. Atomic force microscopy (AFM) images were obtained using the AFM JEOL 4210 equipment, operated in tapping mode [32-41], with standard cantilevers having silicon nitride tips (resonant frequency in the range of 200-300 kHz, spring constant $17.5 \mathrm{~N} / \mathrm{m}$ ). The particles were adsorbed (horizontal adsorption) from their aqueous dispersion for $10 \mathrm{~s}$ on glass. Different areas from $10 \mu \mathrm{m} \times 10 \mu \mathrm{m}$ to $0.5 \mu \mathrm{m} \times 0.5 \mu \mathrm{m}$ were scanned on the same film. The images (2D- topographies, phase and amplitude images, and cross-section profiles for the adsorbed HAPs layer, along a selected direction) were processed by the standard AFM JEOL procedures.

FTIR spectra were measured on $\mathrm{KBr}$ pellets, containing the sample powder with a FTIR spectrometer JASCO 6100 in the $4000-400 \mathrm{~cm}^{-1}$ range of wave numbers, with a $4 \mathrm{~cm}^{-1}$ resolution. Zeta potential measurements were performed using the Malvern Zetasizer Nano-ZS90, on the aqueous dispersions of lyophilized non calcined and calcined samples. BET analysis was achieved with an automated Sorptomatic 1990 instrument, with nitrogen adsorption at $77 \mathrm{~K}$. The calculation of surface area was made in the P/Po range between 0.03 and 0.3 , and the total pore volume was determined at $P / P_{o}=0.95$. Before the analysis the samples were outgassed for $6 \mathrm{~h}$ at $70^{\circ} \mathrm{C}$.

\section{ACKNOWLEDGMENTS}

This work was supported by the Romanian Executive Agency for Higher Education, Research, Development and Innovation Funding (UEFISCDI) through grant 241/2014. 
A. MOCANU, R. BALINT, C. GARBO, L. TIMIS, I. PETEAN, O. HOROVITZ, M. TOMOAIA-COTISEL

\section{REFERENCES}

1. K. Lin, C. Wu, J. Chang, Acta Biomaterialia, 2014, 10, 4071.

2. H.E. Lundager Madsen, F. Christensson, Journal of Crystal. Growth, 1991, 114, 613.

3. C. Garbo, PhD Thesis, Babes-Bolyai University of Cluj-Napoca, Cluj-Napoca, 2016.

4. G. Tomoaia, M. Tomoaia-Cotisel, L. B. Pop, A. Pop, O. Horovitz, A. Mocanu, N. Jumate, L.-D. Bobos, Revue Roumaine de Chimie, 2011, 56, 1039.

5. G. Tomoaia, O. Soritau, M. Tomoaia-Cotisel, L.-B. Pop, A. Pop, A. Mocanu, O. Horovitz, L.-D. Bobos, Powder Technology, 2013, 238, 99.

6. S. Manocha, P. Joshi, B. Patel, L.M. Manocha, Eurasian Chemico-Technological Journal, 2011, 13, 85.

7. G.A. Martínez-Castañón, J.P. Loyola-Rodríguez, N.V. Zavala-Alonso, S.E. Hernández-Martínez, N. Niño-Martínez, G. Ortega-Zarzosa, F. Ruiz, Superficies y Vacío, 2012, 25 (2), 101.

8. S.V. Dorozhkin, Acta Biomaterialia, 2010, 6, 715.

9. E. Kramer, J. Podurgiel, M. Wei, Materials Letters, 2014, 131, 145.

10. Y.X. Pang, X. Bao, Journal of the European Ceramic Society, 2003, 23, 1697.

11. V. Dhand, K.Y. Rhee, S.J. Park. Materials Science and Engineering: C, 2014, $36,152$.

12. H. Ou-Yang, E.P. Paschalis, A.L. Boskey, R. Mendelsohn, Biopolymers, Biospectroscopy, 2000, 57, 129.

13. N. Pleshko, A. Boskey, Mendelsohn, Biophysical Journal, 1991, 60, 786.

14. R.N. Panda, M.F. Hsieh, R.J. Chung, T.S. Chin, Journal of Physics and Chemistry of Solids, 2003, 64, 193.

15. C.B. Baddiel, E.E..Berry, Spectrochimica Acta, 1966, 22, 1407.

16. F. Bakan, O. Laçin, H. Sarac, Powder Technology, 2013, 233, 295.

17. W.L. Suchanek, P. Shuk, K. Byrappa, R.E. Riman, K.S. Ten Huisen, V.F. Janes, Biomaterials, 2002, 23, 699.

18. K. Nakata, T. Kubo, C. Numako, T. Onoki, A. Nakahira, Materials Transactions, 2009, 50, 1046.

19. A.Y. Pataquiva Mateus, C.C. Barrias, C. Ribeiro, M.P. Ferraz, F.J. Monteiro, Journal of Biomedical Materials Research Part A, 2008, 86A, 483.

20. A. Sionkowska, Kozłowska, International Journal of Biological Macromolecules, 2010, 47, 483.

21. D. Gopi, S. Nithiya, E. Shinyjoy, L. Kavitha, Spectrochimica Acta Part A: Molecular and Biomolecular Spectroscopy, 2012, 92, 194.

22. A. Slosarczyk, Z. Paszkiewicz, C. Paluszkiewicz, Journal of Molecular Structure, 2005, 744-747, 657.

23. J.C. Merry, J.R. Gibson, S.M. Best, W. Bonfield, Journal of Material Science: Materials in.Medicine, 1998, 9, 779.

24. K.P. Sanosh, M.C. Chu, A. Balakrishnan, T.N. Kim, S.J. Cho, Bulletin of Materials Science, 2009, 32, 465. 
25. C. Drouet, F. Bosc, M. Banu, C. Largeot, C. Combes, G. Dechambre, C. Estournès, G. Raimbeaux, C. Rey, Powder Technology, 2009, 190, 118.

26. C. Garbo, M. Sindilaru, A. Carlea, G. Tomoaia, V. Almasan, I. Petean, A. Mocanu, O. Horovitz, M. Tomoaia-Cotisel, Particulate Science and Technology, 2017, 35, 29.

27. E. Bouyer, F. Gitzhofer, M.I. Boulos, Journal of Material Science: Materials in Medicine, 2000, 11, 523.

28. J. Rouquerol, D. Avnir, C.W. Fairbridge, D.H. Everett, J.M. Haynes, N. Pernicone, J.D.F. Ramsay, K.S.W. Sing, K.K. Unger, Pure and Applied Chemistry, 1994, $66,1739$.

29. Gh. Tomoaia, A. Mocanu, I. Vida-Simiti, N. Jumate, L.D. Bobos, O. Soritau, M. Tomoaia-Cotisel, Materials Science and Engineering C, 2014, 37, 37.

30. P.T. Frangopol, A. Mocanu, V. Almasan, C. Garbo, R. Balint, G. Borodi, I. Bratu, O. Horovitz, M. Tomoaia-Cotisel, Revue Roumaine de Chimie, 2016, 61337.

31. A. Mocanu, G. Furtos, S. Rapuntean, O. Horovitz, C. Flore, C. Garbo, A. Danisteanu, Gh. Rapuntean, C. Prejmerean, M. Tomoaia-Cotisel, Applied Surface Science, 2014, 298, 225.

32. M.A. Naghiu, M. Gorea, E. Mutch, F. Kristaly, M. Tomoaia-Cotisel, Journal of Material Science and Technology, 2013, 29(7), 628.

33. O. Horovitz, Gh. Tomoaia, A. Mocanu, T. Yupsanis, M. Tomoaia-Cotisel, Gold Bulletin, 2007, 40 (4), 295.

34. M. Tomoaia-Cotisel, A. Tomoaia-Cotisel, T. Yupsanis, Gh. Tomoaia, I. Balea, A. Mocanu, Cs. Racz, Revue Roumaine de Chimie, 2006, 51 (12),1181.

35. A. Danistean, M. Gorea, A. Avram, S. Rapuntean, Gh. Tomoaia, A. Mocanu, C. Garbo, O. Horovitz, M. Tomoaia-Cotisel, Studia UBB Chemia, 2016, 61 (3), 275.

36. Gh. Tomoaia, O. Horovitz, A. Mocanu, A. Nita, A. Avram, C.P. Racz, O. Soritau, M. Cenariu, M. Tomoaia-Cotisel, Colloids and Surfaces B: Biointerfaces, 2015, 135, 726.

37. P.T. Frangopol. D.A. Cadenhead, Gh. Tomoaia, A. Mocanu, M. Tomoaia-Cotisel, Revue Roumaine de Chimie, 2015, 60(2-3), 265.

38. G. Furtos, M. A. Naghiu, H. Declercq, M. Gorea, C. Prejmerean, O. Pana, M. Tomoaia-Cotisel, Journal of Biomedical Materials Research Part B. Applied Biomaterials, 2016, 104 (7), 1290.

39. M. Tomoaia-Cotisel, A. Mocanu, Revista de Chimie (Bucharest), 2008, 59(11), 1230.

40. R.D. Pasca, G. Tomoaia, A. Mocanu, I. Petean, G.A. Paltinean, O. Soritau, M. Tomoaia-Cotisel, Studia UBB Chemia, 2015, 60(3), 257.

41. G. Tomoaia, A. Mocanu, L.D. Bobos, L.B. Pop, O. Horovitz, M. Tomoaia-Cotisel, Studia UBB Chemia, 2015, 60 (3), 265. 
